\title{
Enhanced Rate of Nerve Regeneration and Directional Errors After Sciatic Nerve Injury in Receptor Protein Tyrosine Phosphatase o Knock-Out Mice
}

\author{
Joanna McLean, ${ }^{1 *}$ Jane Batt, ${ }^{2 *}$ Laurie C. Doering, ${ }^{4}$ Daniela Rotin, ${ }^{2}$ and James R. Bain ${ }^{3}$ \\ ${ }^{1}$ Department of Pediatrics, Hospital for Sick Children, University of Toronto, Toronto, Ontario, Canada, M5G 1X8, \\ 2Program in Cell Biology, Hospital for Sick Children, and Department of Biochemistry and Institute of Medical Sciences, \\ University of Toronto, Toronto, Ontario, Canada, M5G 1X8, and Departments of 3 Surgery and 4 Pathology and Molecular \\ Medicine, McMaster University, Hamilton, Ontario, Canada, L8N $3 Z 5$
}

The receptor protein tyrosine phosphatase $\sigma(\mathrm{PTP} \sigma)$ is a member of the mammalian leukocyte common antigen-related (LAR) family. Its expression is developmentally regulated in neuronal tissues. The Drosophila homolog of the mammalian LAR family of phosphatases (DLAR) controls axon guidance during Drosophila embryogenesis. We have demonstrated previously that mice deficient in PTP $\sigma$ have CNS and peripheral nervous system abnormalities. The sciatic nerve in the PTP $\sigma(-/-)$ mice demonstrates an increased number of small diameter fibers and slower nerve conduction velocities compared with PTP $\sigma(+/+)$ or PTP $\sigma(+/-)$ controls. To study whether peripheral nerve regeneration is affected by PTP $\sigma$ activity, we assessed nerve regeneration in the $\mathrm{PTP} \sigma(-/-)$ mouse after three stan-

Successful development of the vertebrate nervous system requires the intricate timing of cellular and molecular processes. Axons follow stereotyped patterns that, to reach a distant target, require precise navigational instruction. This instruction is provided by at least two classes of proteins: classic adhesion molecules and cell surface receptors that control tyrosine phosphorylation within the cell (Van Vactor, 1998; Bixby, 2000; Stoker, 2001). Cell adhesion molecules (CAMs) and substrate adhesion molecules of many classes have been shown to play a role in axonal fasciculation and growth (Rutishauser et al., 1978; Baldwin et al., 1996; Krueger et al., 1996). Although mutations in these proteins affect fasciculation, axonal trajectories are often untouched, suggesting that adhesion molecules may stabilize, rather than direct, neuronal growth (Van Vactor, 1998). Genetic and mutational analyses have suggested that several protein tyrosine phosphatases (PTPs) play an important role in axonal guidance and fasciculation (Van Vactor et al., 1998; Bixby, 2000; Stoker, 2001).

More than 75 PTPs have been identified, with many expressed in the nervous system and some showing neural specificity (Sahin et al., 1995; Schaapveld et al., 1998). Members of the leukocyte common antigen-related (LAR) mammalian subfamily of PTPs

\footnotetext{
Received Sept. 10, 2001; revised Feb. 26, 2002; accepted April 5, 2002.

This work was supported by an Ontario Neurotrauma grant (to J.R.B.) and a Canadian Institute of Health Research (CIHR) grant (to D.R.). D.R. is the recipient of a CIHR Investigator Award and J.B. is supported by a CIHR Fellowship Award. *J.M. and J.B. contributed equally to this manuscript.

Correspondence should be addressed to James R. Bain, 1200 Main Street West, 4E16, Hamilton, Ontario, Canada, L8N 3Z5. E-mail: bainj@hhsc.ca.

Copyright (C) 2002 Society for Neuroscience $0270-6474 / 02 / 225481-11 \$ 15.00 / 0$
}

dard models of sciatic nerve injury. We report that after sciatic nerve crush injury, nerve regeneration was significantly faster in the PTP $\sigma(-/-)$ animals, as determined by histologic, electrophysiologic, and neuromuscular testing. After sciatic nerve transection with immediate microsurgical repair or allografting, PTP $\sigma(-/-)$ nerve fibers demonstrated errors in directional growth compared with controls. We propose that PTP $\sigma$ regulates the axonal regeneration rate and guidance of regenerating fibers.

Key words: protein tyrosine phosphatase $\sigma$; axon guidance; nerve regeneration; sciatic nerve; knock-out mouse; walking track analysis

(LAR, $\mathrm{PTP} \sigma$, and $\mathrm{PTP} \delta$ ), are transmembrane proteins with a cell-adhesion molecule-like ectodomain and intracellular phosphatase domains. PTP $\sigma$ exhibits developmentally regulated expression (Rotin et al., 1994; Wang et al., 1995; Schaapveld et al., 1998; Batt et al., 2002) in embryonic neuronal, neuroendocrine, and epithelial tissues. Expression decreases postnatally and in the adult brain is restricted to areas of high synaptic plasticity. Chick receptor tyrosine phosphatase $\alpha(\mathrm{CRYP} \alpha)$, the avian homolog, shows prominent axonal and growth-cone localization within the embryonic chick (Stoker et al., 1995). A loss-of-function mutant of the Drosophila homolog of LAR-PTP $\sigma-\mathrm{PTP} \delta$ (DLAR) demonstrates directional guidance errors of intersegmental nerve $\mathrm{B}$ (ISNb) (Krueger et al., 1996). This pattern of differential expression and the phenotype of the DLAR mutant support a role for $\mathrm{PTP} \sigma$ in neuronal development.

PTP $\sigma$-deficient mice demonstrate abnormalities of the CNS, peripheral nervous system (PNS), and neuroendocrine system (Elchebly et al., 1999; Wallace et al., 1999; Batt et al., 2002). Phenotypic neurological defects in these mice include spastic movements, tremor, abnormal limb flexion, and defective proprioception. Peripheral nerve electrophysiological analysis demonstrated slower nerve conduction velocities (NCVs) associated with an increased proportion of slow-conducting, small-diameter myelinated fibers in the young PTP $\sigma(-/-)$ mice (Wallace et al., 1999). Normalization of some of these parameters (NCV, nerve morphometrics, tremor, and spasticity) with age suggested that developmental delay contributed to the PTP $\sigma(-/-)$ phenotype. Mice deficient for the other LAR family members, LAR and $\mathrm{PTP} \delta$, also demonstrate nervous system abnormalities (Uetani et al., 2000; Van Lieshout et al., 2001; Xie et al., 2001). Although no 
morphological differences are observed in the uninjured peripheral nerve of LAR-deficient mice, they exhibited a decreased rate of nerve regeneration after sciatic nerve crush injury (Xie et al., 2001). PTP $\sigma$ expression in dorsal root ganglia (DRG) cells has been shown to be responsive to nerve lesion and regeneration of the rat sciatic nerve (Haworth et al., 1998). Collectively, these studies suggest a role for the LAR family of phosphatases in developmental and regenerative growth of the mammalian peripheral nervous system.

This study evaluates the consequences of the lack of PTP $\sigma$ on peripheral nerve regeneration and function using PTP $\sigma$ knockout mice. We demonstrate here by means of histologic and physiologic assessment that the peripheral nerve of the $\mathrm{PTP} \sigma(-/-)$ mouse regenerates faster than in $\mathrm{PTP} \sigma(+/-)$ or $\operatorname{PTP} \sigma(+/+)$ mice and exhibits significant directional errors, suggesting axonal pathfinding defects.

\section{MATERIALS AND METHODS}

Animal model. The PTP $\sigma$ knock-out mouse was generated and characterized as described previously (Wallace et al., 1999). PTP $\sigma(+/-)$ animals are phenotypically indistinguishable from wild-type animals. Three cohorts of PTP $\sigma(-1-)$ can be identified: The majority of PTP $\sigma(-1-)$ animals die within $48 \mathrm{hr}$ after birth $(60 \%)$. Approximately $38 \%$ live until $2-3$ weeks of age and then succumb to a wasting syndrome. Only $2.5 \%$ of PTP $\sigma(-/-)$ mice survive to adulthood, but these mice are $\sim 25-50 \%$ smaller by weight.

Experimental design and surgical procedure. Three standardized nerve injury models were used to evaluate peripheral nerve regeneration: sciatic nerve crush, sciatic nerve transection and microsurgical repair, and sciatic nerve allografting. For each model, 3- to 6-month-old $\operatorname{PTP} \sigma(-/-)$ animals were paired with a sibling $\operatorname{PTP} \sigma(+/-)$ or $\operatorname{PTP} \sigma(+/+)$ control. The sciatic nerves of mice of this age have sufficient caliber to be manipulated microsurgically. The right sciatic nerve was injured under anesthesia in each animal pair. Nerve regeneration was subsequently assessed by histologic evaluation of the insulted sciatic nerve and evaluation of target muscle function (walking track analysis, electrophysiologic testing). All animal housing and surgical interventions were performed in accordance with the Canadian Council on Animal Care Guidelines under institutionally reviewed animal protocols.

Sciatic nerve crush. Sciatic nerve crush injury was performed as described by Seddon (1943). Briefly, the right hindlimb was prepared under Halothane anesthesia (1-3\%) (MTC Pharmaceuticals, Cambridge, Ontario, Canada). Using a sterile technique, a gluteal splitting incision exposed the sciatic nerve $2 \mathrm{~mm}$ distal to the sciatic notch. To create the axonotmesis injury, number 5 jeweller's forceps crushed the sciatic nerve for $15 \mathrm{sec}$. The muscle and skin were closed, and analgesic was administered (Buprenex, $1.5 \mathrm{mg} / \mathrm{kg}$, s.c.; Reckitt and Colman Products, Richmond, VA). Evaluation of nerve regeneration was serially performed until full functional recovery was evident.

Sciatic nerve transection. Sciatic nerve transection injury was performed as described by Seddon (1943). Briefly, the mice were prepared and the sciatic nerve was exposed as described above. The sciatic nerve was surgically divided $2 \mathrm{~mm}$ distal to the sciatic notch and immediately repaired with 10-0 nylon using a standard microsurgical technique. Because full recovery is not evident after transection and repair, evaluation of nerve regeneration is performed at the time of plateau of functional recovery (6 weeks after injury).

Allografts. Simultaneous inhalational Halothane (1-3\%) anesthesia (MTC Pharmaceuticals) was performed on both the PTP $\sigma(-/-)$ animal and its sibling PTP $\sigma(+/-)$ or PTP $\sigma(+/+)$ control. The sciatic nerves of the right hindlimb of each animal were exposed as described above, and matching $1 \mathrm{~cm}$ grafts were procured. The genotypically disparate allografts were then orthotopically repaired to the sciatic nerve deficits via a standard microsurgical technique [i.e., the $\operatorname{PTP} \sigma(-/-)$ graft was repaired to the deficit of its sibling control and vice versa (reciprocal grafting)]. Serial histologic assessment of axonal growth through the graft by light microscopy was subsequently undertaken.

Electrophysiologic assessment. Motor nerve conduction studies were performed both preoperatively and at experiment endpoint, as described previously (Smorto and Basmajian, 1979; Robertson et al., 1993). Briefly, under Halothane anesthesia (MTC Pharmaceuticals) bipolar stimulating electrodes were placed proximally in the sciatic nerve at the level of the sciatic notch and distally in the posterior tibial nerve at the level of the medial malleolus. Recording electrodes were placed in the ipsilateral foot intrinsic muscles. A supramaximal square wave pulse of $0.1 \mathrm{msec}$ duration was applied sequentially at the sciatic notch and medial malleolus, and the motor latency and amplitude of the compound motor action potential (CMAP) was recorded (Neuromax 2000 Electrophysiologic System, Excel Corp., Oakville, Canada). The intersegmental distance between the proximal (sciatic notch) and distal (medial malleolus) electrodes was measured and the intersegmental NCV was calculated using standard formulas (Goodgold and Eberstein, 1983). Direct recordings from the more proximal gastrocnemius muscle were also performed if the CMAP was not detected in the foot intrinsic musculature. Presence or absence of muscle response was compared by $\chi^{2}$ test. CMAP amplitude and NCV comparisons between homozygotes and controls were analyzed by one-way ANOVA and $t$ test. $p<0.05$ was defined as significant.

Neuromuscular assessment: walking track analysis. Hindlimb neuromuscular function was assessed by walking track analysis as described previously (Bain et al., 1989; Brown et al., 1991; Hare et al., 1992, 1993). Briefly, nontoxic paint was applied to the hind feet of each mouse and the animal was then placed into a walking track. Satisfactory prints (based on consistent interprint distance and identifiable print characteristics) were directly measured on a digitizing tablet (Tabletworks; SummaGraphics, Cal Comp Input Technologies Division, Scottsdale, AZ) linked to computerized planimetry software (Sigmascan; Jandel, San Rafael, CA). Foot print length (PL), toe spread (TS), and intermediary TS (IT) (second to fourth) were measured for control (left) and operative (right) sides of each animal. The sciatic function index (SFI) can then be calculated as described previously (Bain et al., 1989). Groups can be compared based on individual footprint characteristics such as PL factor (PLF, difference between experimental and control sides/normal print length), toe spread factor (TSF), and IT factor (ITF) (calculated in the same manner) (Hare et al., 1993). A one-way ANOVA evaluated differences within each experimental group over time and between groups at specified times. $t$ tests were then used if justified by ANOVA. A $p$ value of $<0.05$ was considered significant.

In the rat, gait normalizes by 4 weeks after sciatic nerve crush, but with transection/repair models, gait does not correct completely and function plateaus by 8 weeks after injury (Hare et al., 1992).

Histological assessment. At the completion of the functional/electrophysiologic studies, animal pairs were assigned to either fluorescence immunostaining or light microscopy with or without quantitative crosssectional morphological assessment.

Immunofluorescence. Neurofilament (NF) immunostaining identifies regenerating axons after nerve injury (Sternberger and Sternberger, 1983; Doering, 1992). The mice were sedated with intraperitoneal chloral hydrate and underwent cardiac puncture and perfusion fixation with $0.9 \%$ saline followed by $4 \%$ buffered paraformaldehyde. The sciatic nerve and its terminal branches were dissected out and cryostat sectioning of the procured nerves was performed at the sites illustrated in Figure $3 A, B$. Nerves were sampled at different locations depending on the model of nerve injury used to obtain sections proximal, through, and distal to the injury. Nerves were placed in $30 \%$ sucrose at $4^{\circ} \mathrm{C}$ for $24 \mathrm{hr}$ before cryostat sectioning. Segments were frozen by placement in a plastic weigh boat (maintaining proximal-distal orientation) and immersion in a beaker of 2-methylbutane cooled to $-60^{\circ} \mathrm{C}$ with liquid nitrogen. Samples were embedded in optimal cutting temperature compound (TissueTech; Sakura, Torrance, CA) and $15-\mu \mathrm{m}$-thick longitudinal sections were cut. Sections were transferred to Aptex-coated slides and stored at $-20^{\circ} \mathrm{C}$ before antibody staining.

Slides were washed in PBS for $10 \mathrm{~min}$ at room temperature, blocked, and then incubated overnight at $4^{\circ} \mathrm{C}$ with a 1:2000 dilution of mouse monoclonal anti-neurofilament antibody (RT97 phosphorylated heavy neurofilament subunit; gift to L. Doering from J. N. Wood, University College, London, UK). Slides were washed once with PBS before application of a goat anti-mouse IgG conjugated to fluorescein isothiocyanate or rhodamine (1:100) (Jackson ImmunoResearch, West Grove, PA) for 3 $\mathrm{hr}$ at room temperature. They were then washed three times in PBS, allowed to dry, and coverslipped. Appropriate positive and negative controls (absence of the primary antibody) were used. Sections were viewed subsequently with an epifluorescence microscope to visualize the neurofilament staining. The presence or absence of NF immunoreactivity was noted at standardized locations (see Fig. $3 A, B$ ), and density of staining was recorded by an observer blinded to animal group. The data were organized in a $2 \times 2$ contingency table, and a $\chi^{2}$ test was applied to 
determine whether there was a statistically significant association between the presence of NF immunostaining and mouse genotype (Lang and Secic, 1997). $p<0.05$ was considered statistically significant.

Light microscopy and quantitative morphologic analysis. Mice were killed with intraperitoneal chloral hydrate $(3 \%)$ overdose. The sciatic nerves were atraumatically excised from $5 \mathrm{~mm}$ proximal to the sciatic notch to the trifurcation in the popliteal fossa and processed. Nerves were fixed in $2.5 \%$ glutaraldehyde in a $0.025 \mathrm{~m}$ sodium cacodylate buffer, postfixed in $1 \%$ osmium tetroxide $\left(\mathrm{OsO}_{4}\right)$ in a $0.1 \mathrm{~m}$ sodium cacodylate buffer, dehydrated in ethanol, and embedded in Epon-Analdite. Semithin sections $(1 \mu \mathrm{m})$ were obtained from sites illustrated in Figure $3 A-C$ and stained with toluidine blue in $1 \%$ sodium borate for light microscopy. Quantitative histomorphometric assessment to determine the regenerating nerve fiber number in the crush model was performed. Light microscopic representative fields of the toluidine-blue stained sections were photographed, and the images were digitized. The nerve fiber population was analyzed based on a gray/white scale by computer-linked morphometric software (Sigmascan). Statistical analysis was performed using SPSS 10.0 for Windows (SPSS, Inc., Chicago, IL). ANOVA, using a general linear model with location of assessment as the repeated measure and genotype [PTP $\sigma(-/-)$ or sibling] and time as the group effects, was performed. An overall $p$ value of $<0.05$ was defined as significant. An experienced pathologist, blinded to the experimental group, assessed the extent of Wallerian degeneration present in the nerve segments, assessed the state of the perineurium, and graded the extent of extrafascicular regeneration (regeneration outside of the original nerve fascicle) in the transection and allograft models as normal or increased. To determine whether the extent of extrafascicular regeneration was significantly different between groups in the allograft model, the data were organized in contingency tables and analyzed by a $\chi^{2}$ test assessing the association between the genotype of the environment through which the fibers were regenerating and the presence of increased extrafascicular regeneration (Lang and Secic, 1997). A $p$ value of $<0.05$ was defined as significant.

$L a c Z$ staining. PTP $\sigma(-/-), \operatorname{PTP} \sigma(+/-)$, and PTP $\sigma(+/+)$ mice underwent sciatic nerve transection as described previously and were killed 2 weeks after injury. The sciatic nerves in continuity with their DRG from both the operated and contralateral control hindlimbs were excised and fixed in a $0.1 \mathrm{M}$ sodium phosphate buffer, $\mathrm{pH} 7.9$, containing $1 \%$ formaldehyde, $0.1 \%$ glutaraldehyde, $2 \mathrm{mM} \mathrm{MgCl}_{2}$, and $5 \mathrm{~mm}$ EGTA for $4 \mathrm{hr}$ at $4^{\circ} \mathrm{C}$. Nerves were subsequently washed with four exchanges of a wash buffer $(2 \mathrm{mM} \mathrm{MgCl} 2,0.01 \%$ deoxycholate, and $0.02 \% \mathrm{NP}-40$ in 0.1 M sodium phosphate buffer, $\mathrm{pH}$ 7.9) at room temperature over $2 \mathrm{hr}$. The tissue was then incubated in PBS containing $5 \mathrm{~mm}$ ferricyanide, $5 \mathrm{~mm}$ ferrocyanide, $2 \mathrm{mM} \mathrm{MgCl}$ and $0.1 \mathrm{mg} / \mathrm{ml}$ 5-bromo-4-chloro-3-indolyl- $\beta$ D-galactopyranoside (Roche, Hertforshire, UK) overnight at $37^{\circ} \mathrm{C}$. Nerves were subsequently rinsed in $70 \% \mathrm{EtOH}$, embedded in paraffin, and sectioned $(10 \mu \mathrm{m})$.

\section{RESULTS}

Three standardized nerve injury models were used to evaluate peripheral nerve regeneration: sciatic nerve crush, sciatic nerve transection and microsurgical repair, and sciatic nerve allografting. PTP $\sigma(+/-)$ animals are phenotypically indistinguishable from $\mathrm{PTP} \sigma(+/+)$ animals and were used interchangeably as controls throughout the experiments.

\section{Sciatic nerve crush}

Sciatic nerve crush (axonotmesis injury) is a model of fully reversible nerve injury (Seddon, 1943). Although the axonotmesis injury requires a regenerative response from the proximal nerve, no directional challenges face the regenerating fibers because they are directed down the intact endoneurial sheath.

After crush injury, the PTP $\sigma(-/-)$ mice demonstrated a more rapid return of muscle function electrophysiologically, as evidenced by greater amplitude of the CMAP compared with control animals (Fig. 1). The amplitude of the CMAP is directly proportional to the number of nerve fibers innervating the muscle. These data therefore suggest a faster rate of nerve regeneration in the $\mathrm{PTP} \sigma(-/-)$ mice. Measurements were taken from two target muscles: the gastrocnemius, which is $15 \mathrm{~mm}$ from the
A

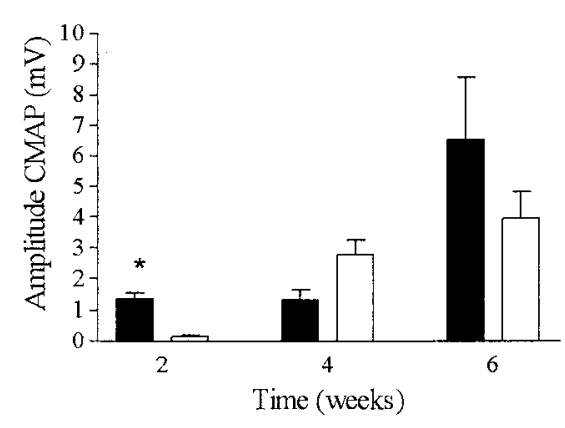

$-/-$ gastro $\square+/+$ gastro

B

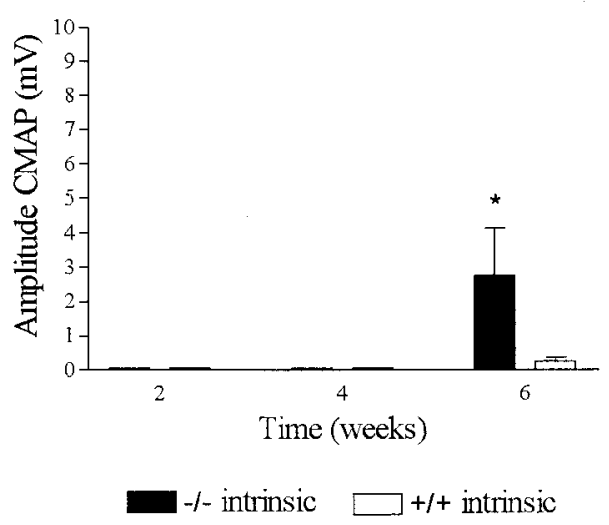

Figure 1. Electrophysiologic assessment of sciatic nerve function after axonotmesis. The amplitude of the CMAP (mean \pm SEM) recorded from the gastrocnemius $(A)$ or foot intrinsics $(B)$ reflects and is proportional to the degree of reinnervation of the muscle. PTP $\sigma(-/-)$ mice $(n=11)$ demonstrated an earlier return of electrophysiologic response (as indicated by a greater amplitude of the CMAP) in the gastrocnemius muscle at 2 weeks $\left({ }^{*} p<0.05\right.$; Student's $t$ test) and intrinsic muscles at 6 weeks $(* p<0.05$; Student's $t$ test) compared with PTP $\sigma(+/-)$ or $\operatorname{PTP} \sigma(+/+)$ sibling controls $(n=11)$.

crush site, and the foot intrinsics, which are $\sim 30 \mathrm{~mm}$ distal to the crush. At 2 weeks after injury, the CMAP amplitude recorded from the gastrocnemius muscle of the PTP $\sigma(-/-)$ animals was significantly greater than that of the sibling controls (Fig. 1A), indicating that more nerve fibers had regenerated to and reinnervated the gastrocnemius of the $\operatorname{PTP} \sigma(-/-)$ mice. By 4 weeks after injury, the sibling controls had "caught up" to the PTP $\sigma(-/-)$ mice, with no significant difference noted in the amplitude of the CMAP between the groups. At 6 weeks, a response became evident in the more distal musculature, the foot intrinsics, with the CMAP amplitude being again greater in the PTP $\sigma(-/-)$ mice compared with control PTP $\sigma(+/-)$ and PTP $\sigma(+/+)$ mice (Fig. 1B). Therefore, both the gastrocnemius and foot intrinsic muscles demonstrated sequentially faster reinnervation in the $\mathrm{PTP} \sigma(-/-)$ mice, suggesting a faster rate of nerve regeneration in the knock-out animal.

The differences noted in the rate of return of the CMAP cannot be attributed to a size discrepancy between the experimental and control mice. Although the adult PTP $\sigma(-/-)$ mice are $25-50 \%$ smaller by weight than their $\mathrm{PTP} \sigma(+/-)$ or 
PTP $\sigma(+/+)$ siblings, they are essentially lean mice with no statistically significant differences in the length of their hindlimb nerves. The sciatic nerve trif urcates midway down the leg into the tibial, sural, and peroneal nerves. The sciatic and a proximal branch of the tibial innervate the gastrocnemius muscle. The distal tibial nerve terminates in and innervates the foot intrinsic muscles. The length of the sciatic and proximal tibial nerves innervating the gastrocnemius was $13.8 \pm 1.8 \mathrm{~mm}$ in the $\mathrm{PTP} \sigma(-/-)$ mice $(n=6)$ and $15.9 \pm 2.7 \mathrm{~mm}$ in the $\mathrm{PTP} \sigma(+/-) / \operatorname{PTP} \sigma(+/+)$ mice $(n=7)(p>0.05$; not significant by Student's $t$ test $)$. Similarly, the length of the sciatic and distal tibial innervating the foot intrinsic muscles was $29.3 \pm 3.6 \mathrm{~mm}$ in the PTP $\sigma(-/-)$ mice $(n=10)$ and $33.0 \pm 4.4 \mathrm{~mm}$ in the $\mathrm{PTP} \sigma(+/-) / \mathrm{PTP} \sigma(+/+)$ mice $(n=7)(p>0.05$; not significant by Student's $t$ test $)$.

Preoperative nerve conduction studies confirmed marginally slower NCVs and an intact CMAP in the PTP $\sigma(-/-)$ mice compared with sibling $\mathrm{PTP} \sigma(+/-)$ or PTP $\sigma(+/+)$ controls, as reported previously (Wallace et al., 1999) in mice of this age group (data not shown). The slower NCV seen in the $\mathrm{PTP} \sigma(-/-)$ group is the result of an increased proportion of slowly conducting smaller diameter fibers (Wallace et al., 1999), which seems to stem from developmental delay of the $\mathrm{PTP} \sigma(-/-)$ mice. As anticipated, at the endpoint in this study, the NCV approached the preoperative baseline in all animals, indicating full electrophysiologic recovery (data not shown).

After crush injury, the serial walking track analyses demonstrated significant differences in the rate of recovery of normal gait between the PTP $\sigma(-/-)$ mice and the sibling controls (Fig. 2). Hindlimb neuromuscular function can be measured noninvasively by evaluating gait. Measurements of the footprints from the experimental side can be serially collected to follow nerve recovery, because characteristics of the footprint reflect the functional muscle groups. Footprint analysis and measurement of specific parameters are taken to determine the PLF, TSF, and ITF (Bain et al., 1989). Formulas have also been derived and validated that combine all relevant footprint measurements into a global index of function (i.e., SFI) (Bain et al., 1989). Better factor scores indicate a more normal footprint and gait. Significantly better TSF and ITF scores were measured at 1 and 1.5 weeks, respectively $(p<0.05)$ in the $\mathrm{PTP} \sigma(-/-)$ mice compared with $\mathrm{PTP} \sigma(+/-)$ and $\mathrm{PTP} \sigma(+/+)$ control mice. The SFI score was also significantly improved in the PTP $\sigma(-/-)$ mice compared with controls at 1 and 1.5 weeks after injury. After 2 weeks, there were no significant differences noted as the $\mathrm{PTP} \sigma(+/-)$ and $\operatorname{PTP} \sigma(+/+)$ mice "catch up" to the $\operatorname{PTP} \sigma(-/-)$ mice. By 4 weeks, all test groups had normalized their walking track parameters and had full recovery of gait. These results suggest a faster rate of initial nerve regeneration in the $\operatorname{PTP} \sigma(-/-)$ animal.

Sciatic nerves for NF fluorescent immunostaining were obtained at $0,2,4$, and 6 weeks after axonotmesis injury. The sciatic nerves were sectioned for analysis as illustrated in Figure $3 A$. Nerve sections were examined blinded to experimental group and assessed for the presence of NF immunofluorescence. NF immunoreactivity was evident in the distal segment of $67 \%$ of PTP $\sigma(-/-)$ mice by week 2 but was only seen in $50 \%$ of the $\operatorname{PTP} \sigma(+/-)$ or PTP $\sigma(+/+)$ animals $\left(p<0.05\right.$ by $\chi^{2}$ test) (Fig. $4 A, B)$. The earlier appearance of neurofilaments at a precisely specified distance distal to the crush injury is evidence for a faster rate of neural regeneration in the $\mathrm{PTP} \sigma(-/-)$ mice.

After crush injury, the evaluation of the nerve cross sections by light microscopy revealed characteristic changes of Wallerian degeneration in the distal nerve stump and concurrent axonal
A
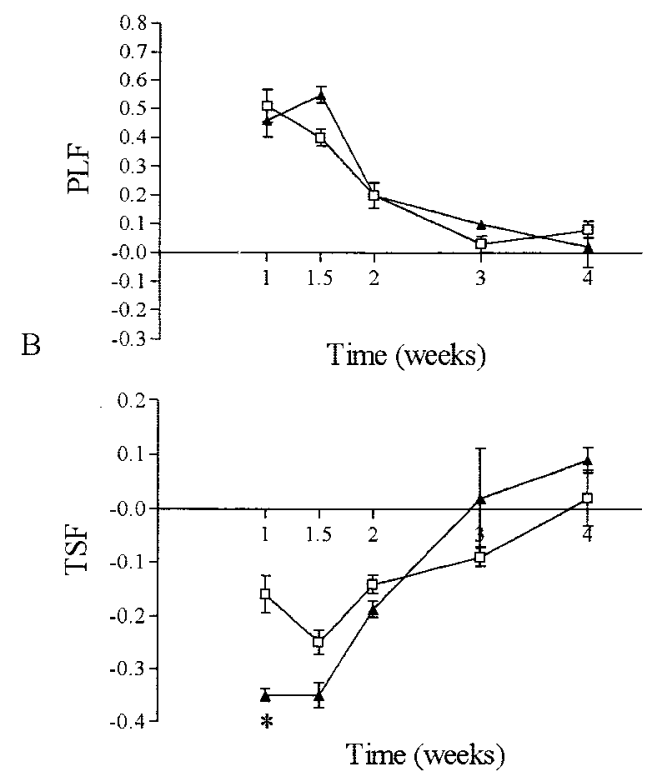

C

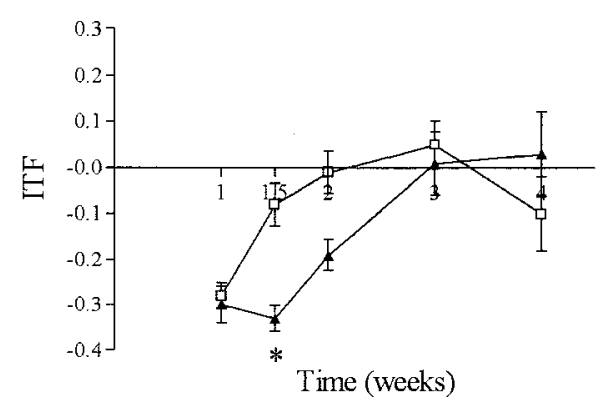

$\mathrm{D}$

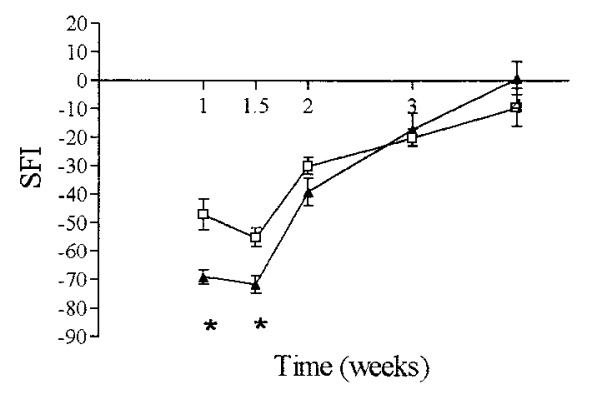

$\rightarrow \operatorname{PTP\sigma }(+/+) \quad \longrightarrow \operatorname{PTP\sigma }(-/-)$

Figure 2. Walking track analysis after axonotmesis. Each representative print characteristic is shown: $A$, PLF; $B$, TSF; $C$, ITF; $D$, SFI (mean \pm SEM). For each factor, the value 0 represents normal function (no difference between experimental and normal sides). Significantly better TSF and SFI scores at 1 week $\left({ }^{*} p<0.05\right)$ and significantly better ITF and SFI scores at 1.5 weeks $\left({ }^{*} p<0.05\right)$ were noted in the PTP $\sigma(-/-)$ animals $(n=12)$ compared with controls $(n=11)$. This is indicative of faster regeneration of motor axons to correct motor targets. There were no significant differences noted after 2 weeks, because the PTP $\sigma(+/-)$ or $\operatorname{PTP} \sigma(+/+)$ mice catch up to the $\operatorname{PTP} \sigma(-/-)$ mice. By 4 weeks, each factor score corrected to zero (normal function) as expected for this injury. 


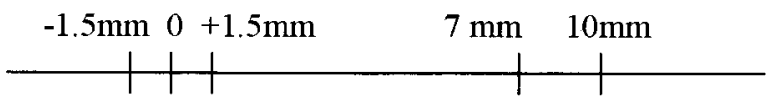

Proximal

distal

A

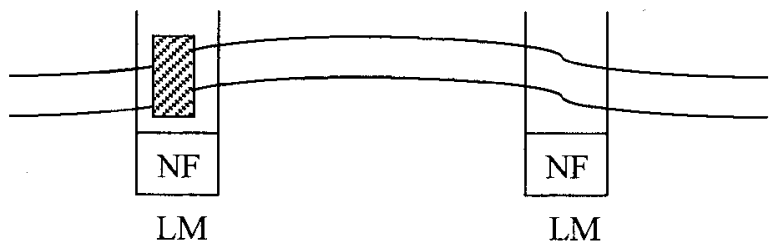

B

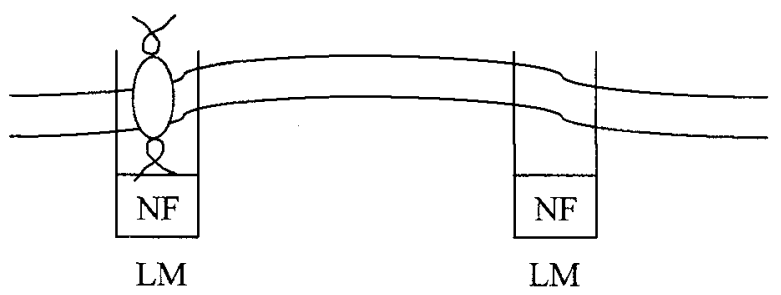

C
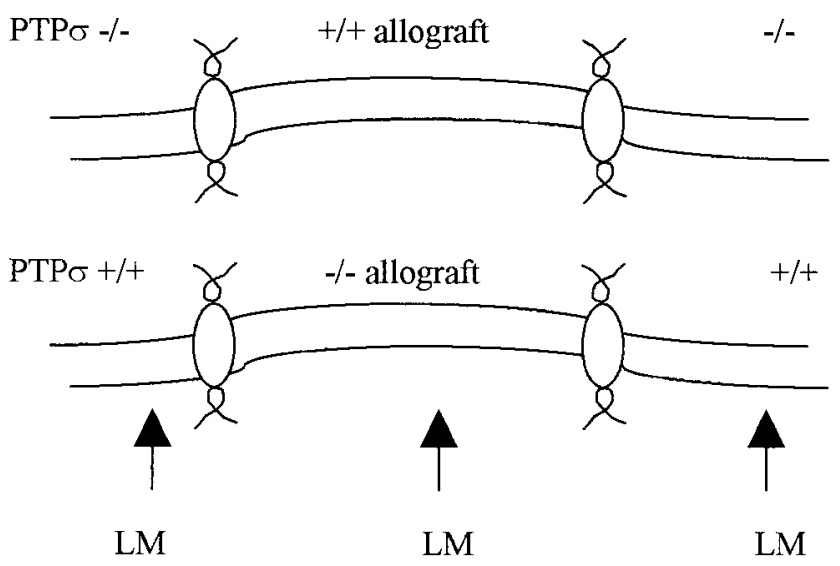

Figure 3. Sites of surgical intervention and histologic assessment for the three experimental models. $A$, Sciatic nerve axonotmesis (crush). The cross-hatched bar represents the region of crush. Three millimeter longitudinal samples at both the injury site and distally, in addition to transverse sections at the injury site and distally, were obtained for neurofilament immunofluorescence $(N F)$ and light microscopy $(L M)$, respectively. $B$, Sciatic nerve transection and repair. The suture represents the site of transection and immediate microsurgical repair. Three millimeter longitudinal samples at the injury site and distally, in addition to transverse sections (proximal and distal), were obtained for NF and LM, respectively. $C$, A 1-cm-long phenotypically disparate allograft was repaired to the transection deficit in the PTP $\sigma(-/-)$ and PTP $\sigma(+/-)$ or PTP $\sigma(+/+)$ mice. Sections for LM were obtained as indicated by the arrows (proximal, through the graft, and distal).

regeneration (data not shown). Quantitative evaluation of the regenerating fiber population confirmed earlier regeneration in the $\mathrm{PTP} \sigma(-/-)$ animals compared with $\mathrm{PTP} \sigma(+/-)$ and $\mathrm{PTP} \sigma(+/+)$ controls. The regenerating fiber number (Fig. 5) was significantly greater at earlier stages at matched sampling sites in the PTP $\sigma(-/-)$ animals. The presence of more fibers at a standardized distance $(10 \mathrm{~mm})$ from the crush site confirms a faster rate of regeneration in the knock-out mice. Differences between
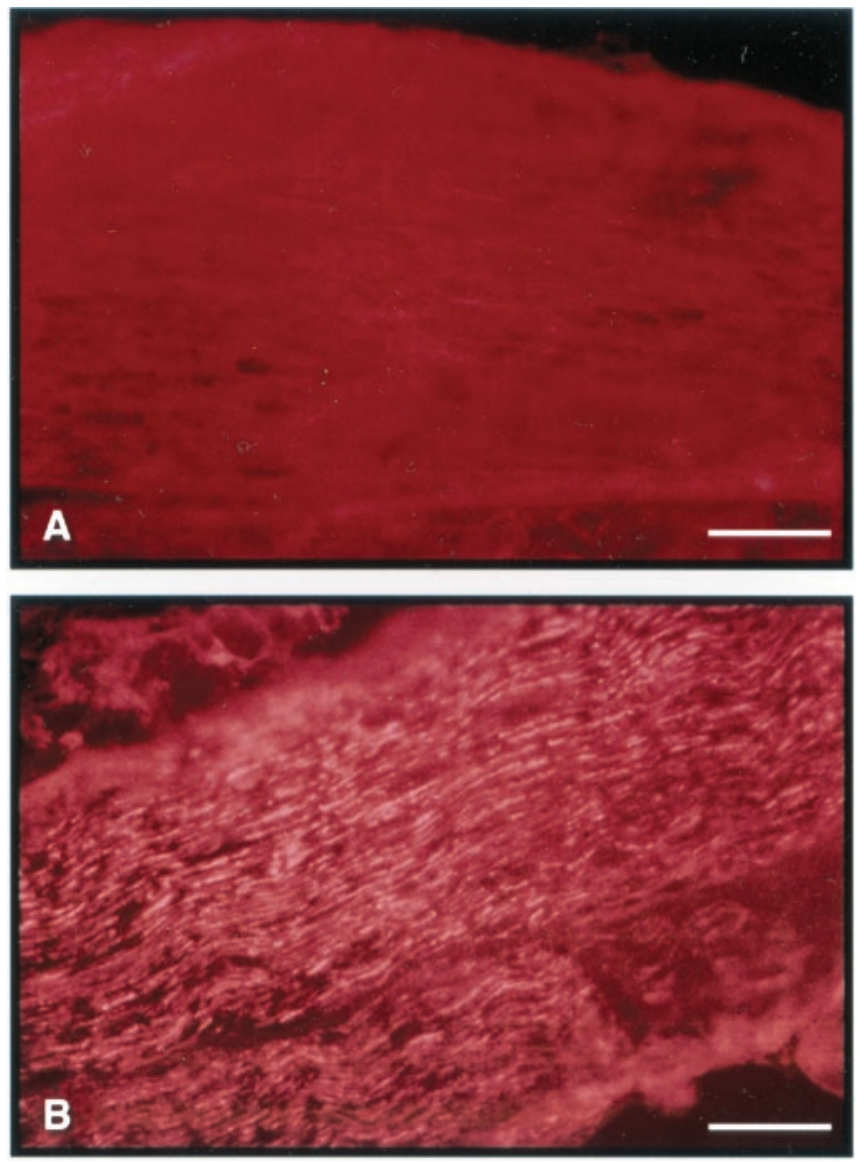

Figure 4. RT97 neurofilament immunostaining of crushed nerve. Sections are $3 \mathrm{~mm}$ longitudinal standardized for distance from crush site (10 $\mathrm{mm})$. Adequate sections for visualization were obtained from 10 $\mathrm{PTP} \sigma(+/-) / \mathrm{PTP} \sigma(+/+)$ controls and $13 \mathrm{PTP} \sigma(-/-)$ animals. At 2 weeks after injury, NF immunostaining (bright fluorescent red) is evident in the PTP $\sigma(-/-)$ mouse $(B)$ but only background staining (muted red) is seen in the $\mathrm{PTP} \sigma(+/+)$ control $(A)$. Scale bar, $100 \mu \mathrm{m}$.

experimental groups diminished by 3 weeks after injury. In all groups, as anticipated, improvement was observed over time but did not normalize by 3 weeks.

\section{Sciatic nerve transection and immediate repair}

Sciatic nerve transection and microsurgical repair is a more severe insult than axonotmesis. It is a dual challenge testing both the regenerative capacity of the nerve and the axonal guidance system because the endoneurial sheath has been completely disrupted. Complete recovery does not occur after this injury, and the degree of function regained is often extremely variable (Seddon, 1943).

After nerve transection and repair, as expected, large variance in CMAP and walking track parameters was noted within all test groups. No statistically significant difference was seen in the recovery of CMAP amplitude or normal gait between the $\operatorname{PTP} \sigma(-/-)$ and $\mathrm{PTP} \sigma(+/-)$ or $\mathrm{PTP} \sigma(+/+)$ controls (data not shown).

NF immunostaining was performed on segments procured after transection and immediate repair as illustrated in Figure $3 B$. After nerve transection and repair, it is common to see some fiber misalignment. However, in the $\operatorname{PTP} \sigma(-/-)$ animals we saw a much greater proportion of disorganized fibers at the neuror- 


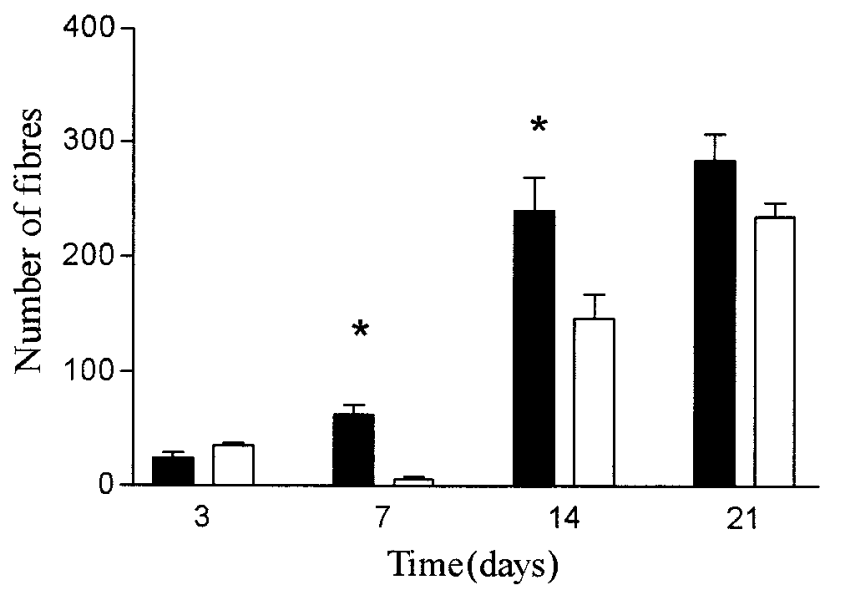

$\square-/-\quad \square+/+$

Figure 5. Quantitative nerve fiber counts (mean \pm SEM) performed on semithin light-microscopy cross sections $10 \mathrm{~mm}$ distal to nerve crush at matched sites (Fig. 3A). PTP $\sigma(-/-)$ animals had significantly more fibers regenerate into the distal stump by days 7 and 14 compared with controls. By $21 \mathrm{~d}$, the PTP $\sigma(+/-)$ and PTP $\sigma(+/+)$ controls had caught up and had an equivalent number of fibers $\left({ }^{*} p<0.05 ; n=4\right.$ mice/group).

rhaphy site (Fig. 6A) compared with the sibling controls (Fig. 6B). The distal segment of the nerve in the control animals had straighter and more parallel NF-positive fibers (Fig. 6D) compared with $\mathrm{PTP} \sigma(-/-)$ mice (Fig. 6C). This suggests difficulties with axonal pathfinding in the $\mathrm{PTP} \sigma(-/-)$ mice.

After sciatic nerve transection with immediate repair, the evaluation of the nerve cross sections by light microscopy revealed characteristic changes of Wallerian degeneration in the distal nerve stump and concurrent axonal regeneration (data not shown). Several qualitative differences between the test groups were indicative of errors in axonal guidance in the $\operatorname{PTP} \sigma(-/-)$ mice. After transection in the normal peripheral nerve, the large majority of axons will correctly regenerate into the established fascicles of the distal segment, but it is typical for a small proportion of fibers to err and regenerate outside the fascicles
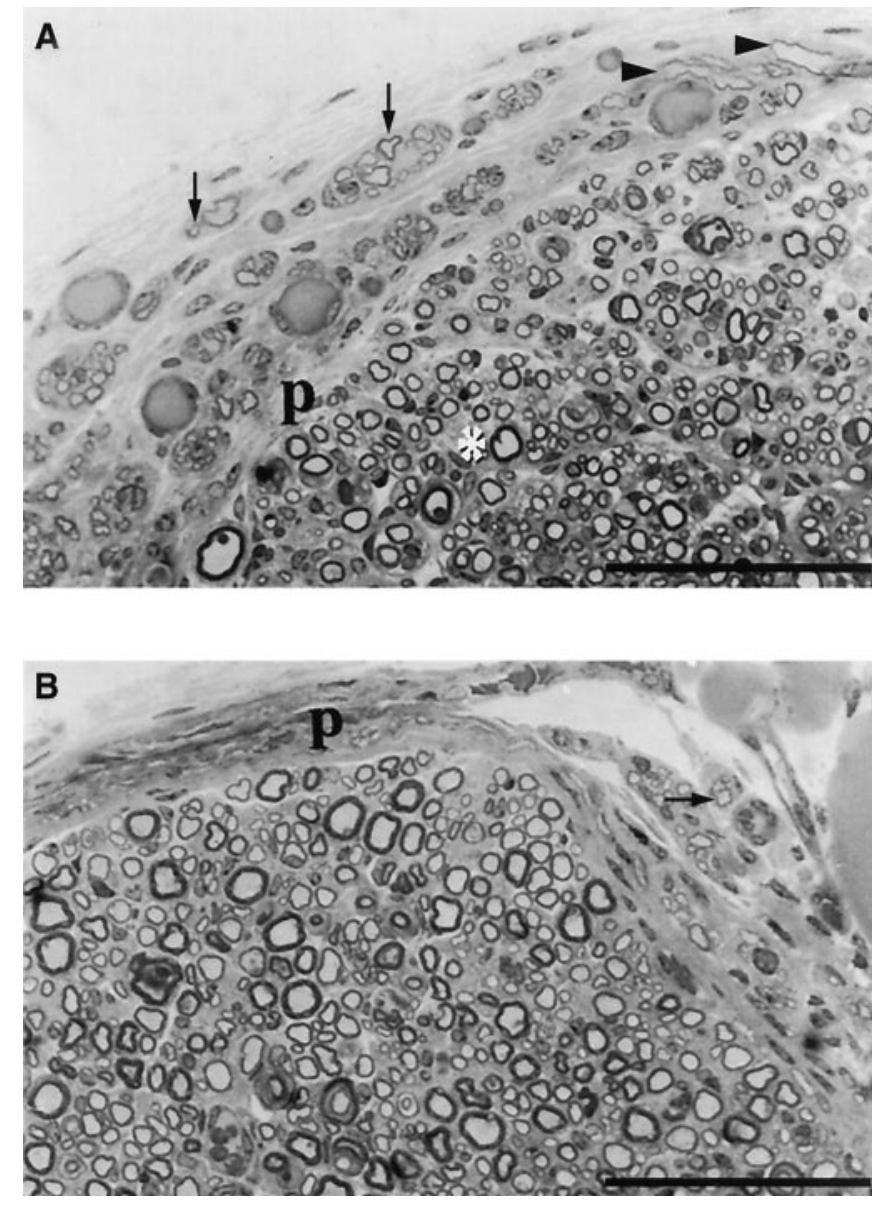

Figure 7. Light microscopic evaluation of sciatic nerve cross sections from the transection model. In $\mathrm{PTP} \sigma(-/-)$ mice, more disoriented, transverse, and oblique fibers are evident at the repair site $(A)$ compared with PTP $\sigma(+/-)$ or PTP $\sigma(+/+)$ controls $(B)$. Arrows mark extrafascicular fibers within mini-fascicles, arrowheads indicate misdirected oblique fibers, the perineurium is marked $p$, and an asterisk marks a normal circumferential cross-section fiber. Scale bar, $100 \mu \mathrm{m}$.

Figure 6. RT97 neurofilament immunostaining of longitudinal sections through transected and repaired nerves. In PTP $\sigma(-/-)$ animals, more disoriented, transverse, and oblique fibers are evident at the repair site $(A)$ and distally $(C)$ compared with $\mathrm{PTP} \sigma(+/-)$ or $\mathrm{PTP} \sigma(+/+)$ controls $(B$, repair site; $D$, distally). Arrows mark "end on" transverse fibers, and the asterisk marks one of the oblique fibers. The large black holes in $A$ and $B$ are the suture sites. Scale bar, $100 \mu \mathrm{m}$.
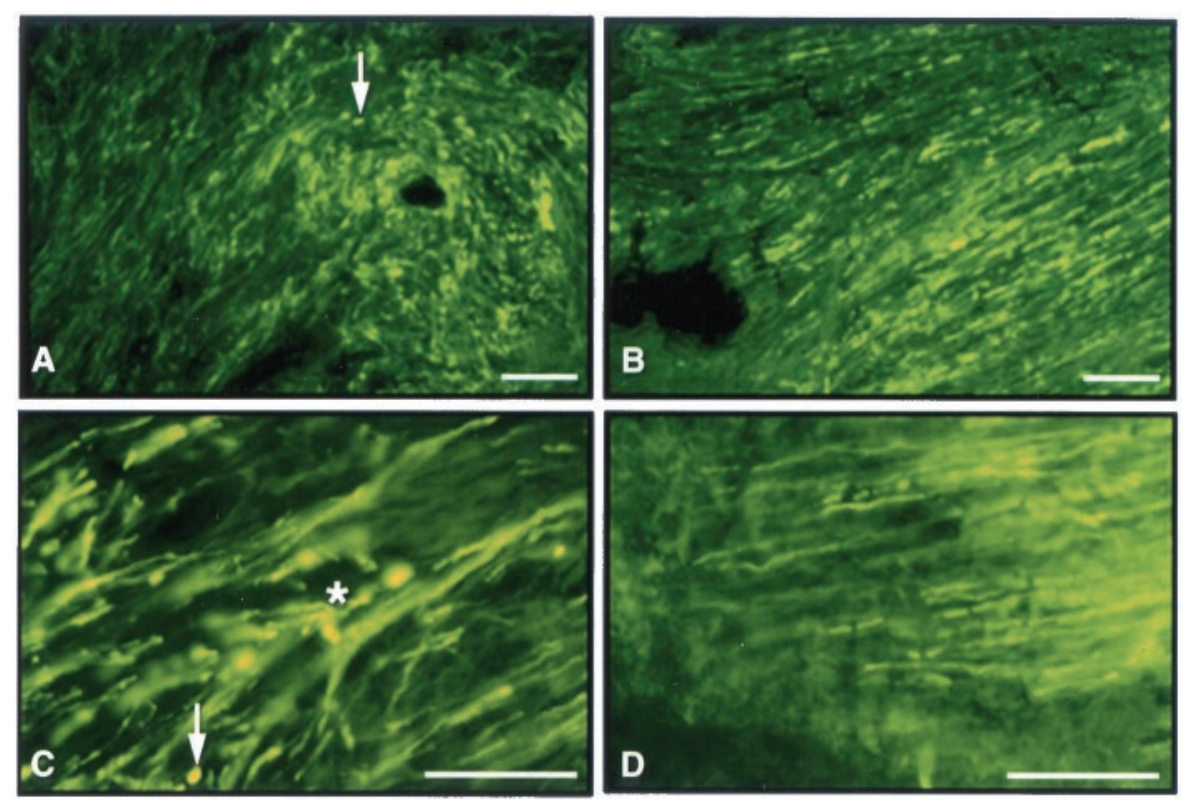

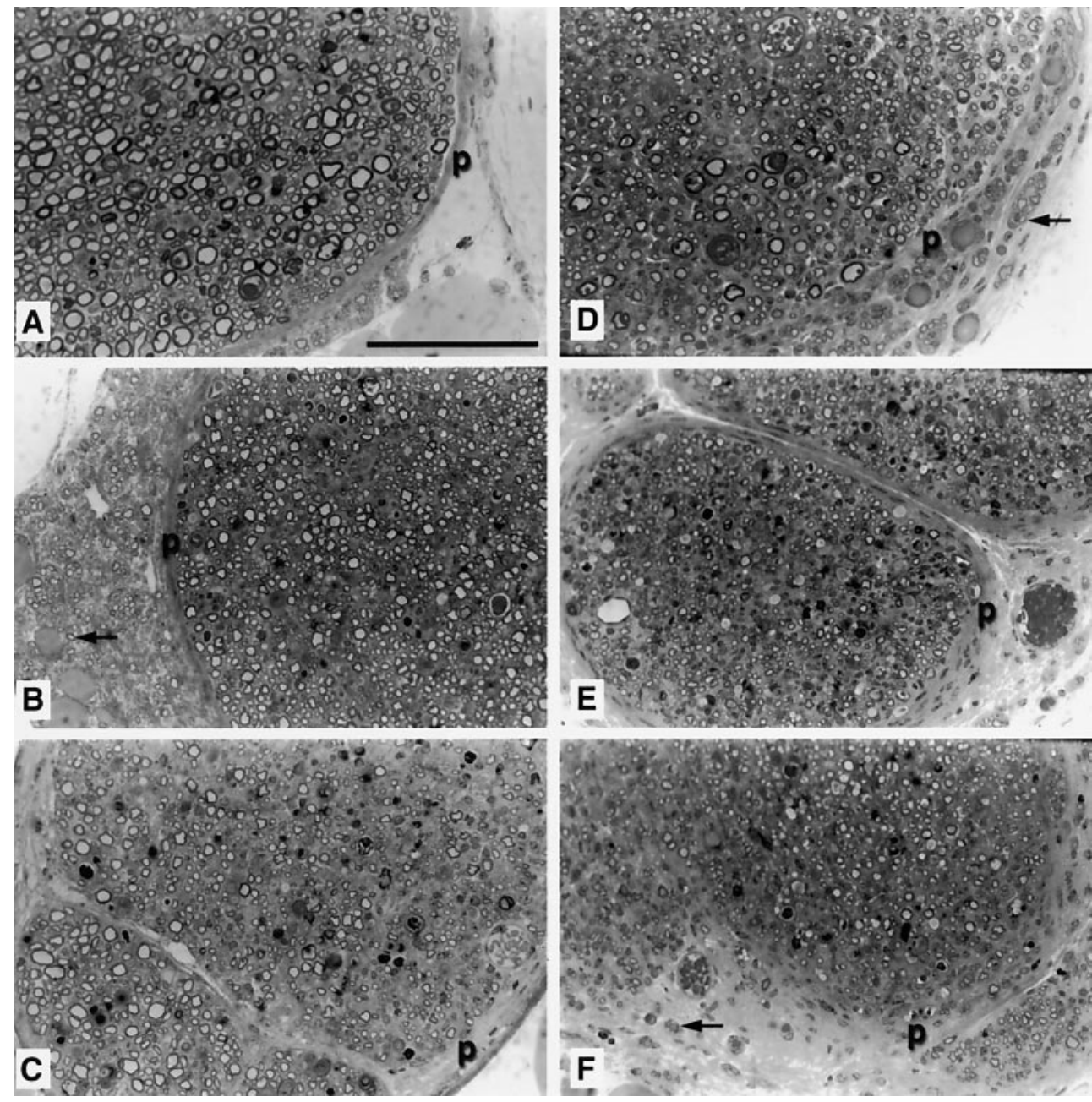

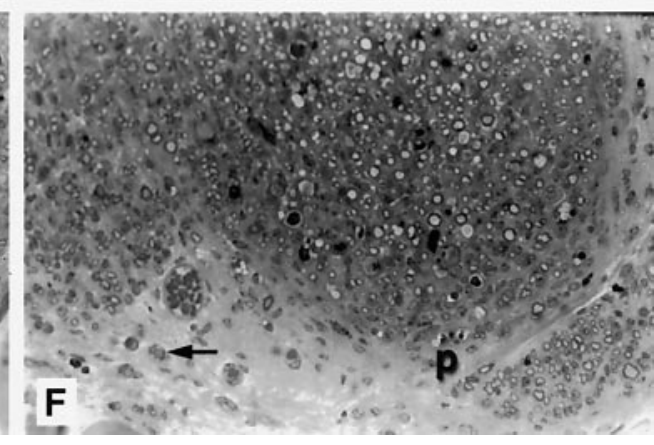

Figure 8. Light-microscopic evaluation of sciatic nerve transverse sections from the allograft model. The typical histologic pattern of regeneration in the grafted animals is shown proximal to the graft $(A$, $D)$, through the midportion of the allograft $(B, E)$, and distal to the graft $(C, F)$. Axons that grew outside the nerve (extrafascicular) have a small likelihood of regaining contact to their original end organ. An increased proportion of extrafascicular fibers is seen proximally $(D)$ and distally $(F)$ in the $\operatorname{PTP} \sigma(-/-)$ animal, with some correction of growth through the $\operatorname{PTP} \sigma(+/-)$ or $\operatorname{PTP} \sigma(+/+)$ allograft $(E)$. In contrast, the organized regeneration of $\mathrm{PTP} \sigma(+/-)$ and $\mathrm{PTP} \sigma(+/+)$ fibers proximally and distally $(A$ and $C$, respectively) is lost as the axons traverse the PTP $\sigma(-/-)$ graft $(B)$. Arrows indicate extrafascicular fibers. $p$, Perineurium. Scale bar, $100 \mu \mathrm{m}$. (i.e., extrafascicular regeneration). In the $\mathrm{PTP} \sigma(+/-)$ and PTP $\sigma(+/+)$ control animals, we noted a normal proportion of extrafascicular fibers consistently arranged in "mini-fascicles" within a well organized perineurium (Fig. $7 B$ ). In contrast, there was an increase in the proportion of the extrafascicular fibers in the $\mathrm{PTP} \sigma(-/-)$ animals and a large numbers of fibers that were obliquely or transversely oriented (Fig. 7A). In addition, the perineurium generally tended to be thinner and less well organized in the PTP $\sigma(-/-)$ group. Collectively, these findings suggest an increased incidence of directional errors in the regenerating axon of the $\operatorname{PTP} \sigma(-/-)$ mouse.

\section{Allografts}

Sciatic nerve allografting was undertaken to assess the interaction of the regenerating axonal fibers, the Schwann cell population, and other elements of the regenerative milieu.

Striking differences in patterns of axonal regeneration were seen in the allografted animals. At 6 weeks after allografting, sciatic nerve segments were obtained from sites as illustrated in Figure $3 C$. In the proximal nerve segment, $\mathrm{PTP} \sigma(-/-)$ mice demonstrated extensive extrafascicular regeneration with a large number of fibers moving retrograde (i.e., proximally) (Fig. $8 D$ ) in comparison with $\mathrm{PTP} \sigma(+/-)$ and $\mathrm{PTP} \sigma(+/+)$ controls (Fig. $8 A)$. These PTP $\sigma(-/-)$ recipients of $\mathrm{PTP} \sigma(+/-)$ and $\mathrm{PTP} \sigma(+/+)$ grafts seemed to have some correction of their directional errors within the graft, because sampling here re- vealed fewer extrafascicular fibers (Fig. $8 E$ ). In contrast, when the control PTP $\sigma(+/-)$ and $\mathrm{PTP} \sigma(+/+)$ fibers regenerated into the PTP $\sigma(-/-)$ graft, directional cues seemed to be lost, because extensive extrafascicular regeneration was evident (Fig. 8B). Once the fibers had completely traversed the graft and re-entered the host distal nerve, the patterns of regeneration reversed. $\mathrm{PTP} \sigma(-/-)$ fibers resumed an inaccurate course in the distal nerve segment, with increased extrafascicular regeneration (Fig. $8 F$ ). However, there were a limited number of extrafascicular fibers observed in the $\mathrm{PTP} \sigma(+/-)$ and $\mathrm{PTP} \sigma(+/+)$ distal segments (Fig. 8C).

The extent of extrafascicular regeneration in all microscopic sections was graded as normal or increased to permit statistical analysis of the data. In the $\mathrm{PTP} \sigma(+/-) / \operatorname{PTP} \sigma(+/+)$ mice (receiving the homozygote allograft; $n=9)$, extensive extrafascicular regeneration was seen in the proximal nerve segment of $33 \%$ of animals, increased dramatically to $100 \%$ of animals within the graft, and was noted in only $12.5 \%$ in the distal nerve. In contrast, in the PTP $\sigma(-/-)$ mice (receiving the heterozygote/wild-type allograft; $n=7$ ), extensive extrafascicular regeneration was evident in the proximal nerve segment of $57 \%$ of animals but decreased to $40 \%$ of animals within the graft. A $\chi^{2}$ test assessing the association between the genotype of the environment and the extent of extrafascicular regeneration was statistically significant $(p=0.0341)$.

Because the $\beta$-galactosidase gene replaces PTP $\sigma$ in the knock- 

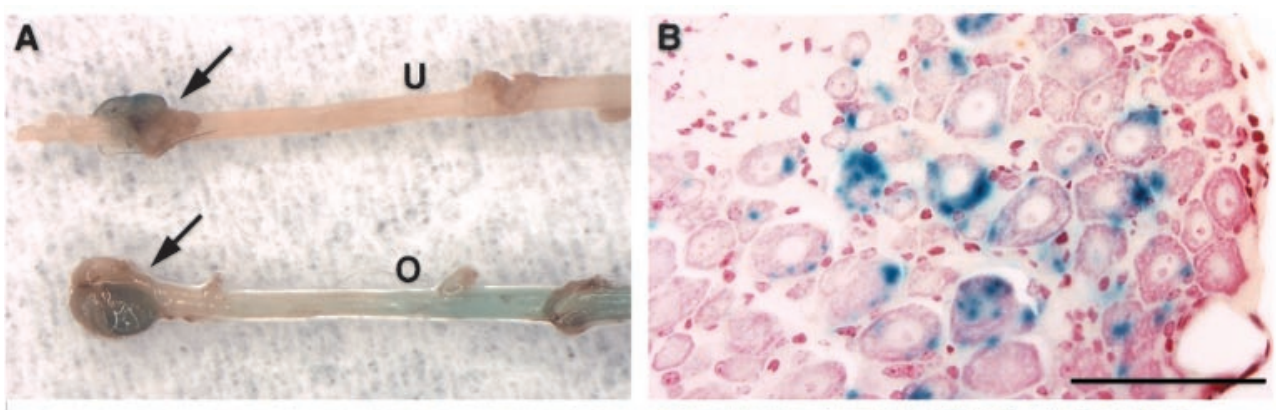

Figure 9. LacZ staining of the operated $(O)$ and contralateral unoperated $(U)$ sciatic nerves 2 weeks after transection injury in a $\mathrm{PTP} \sigma(-/-)$ mouse. Blue LacZ staining indicates the pattern of $\mathrm{PTP} \sigma$ expression, because the $\mathrm{PTP} \sigma$ knock-out cassette contains the $\beta$-galactosidase gene. LacZ staining is evident in the DRG $(A$; arrows $)$ and is markedly increased in the operated sciatic nerve $(C)$, particularly in the area of the advancing growth cone $(E)$. LacZ staining is apparent in the sensory cell bodies of the DRG $(B)$. Scale bar, 100 $\mu \mathrm{m}$. $D$, A transverse section taken through the proximal end of the regenerating growth cone reveals a cobblestone pattern of LacZ staining in the supportive milieu of the axon. Scale bar, $100 \mu \mathrm{m} . F$, Higher magnification localizes LacZ staining to the Schwann cell. Scale bar, $20 \mu \mathrm{m}$. No LacZ staining was evident in the $\operatorname{PTP} \sigma(+/+)$ controls (data not shown).
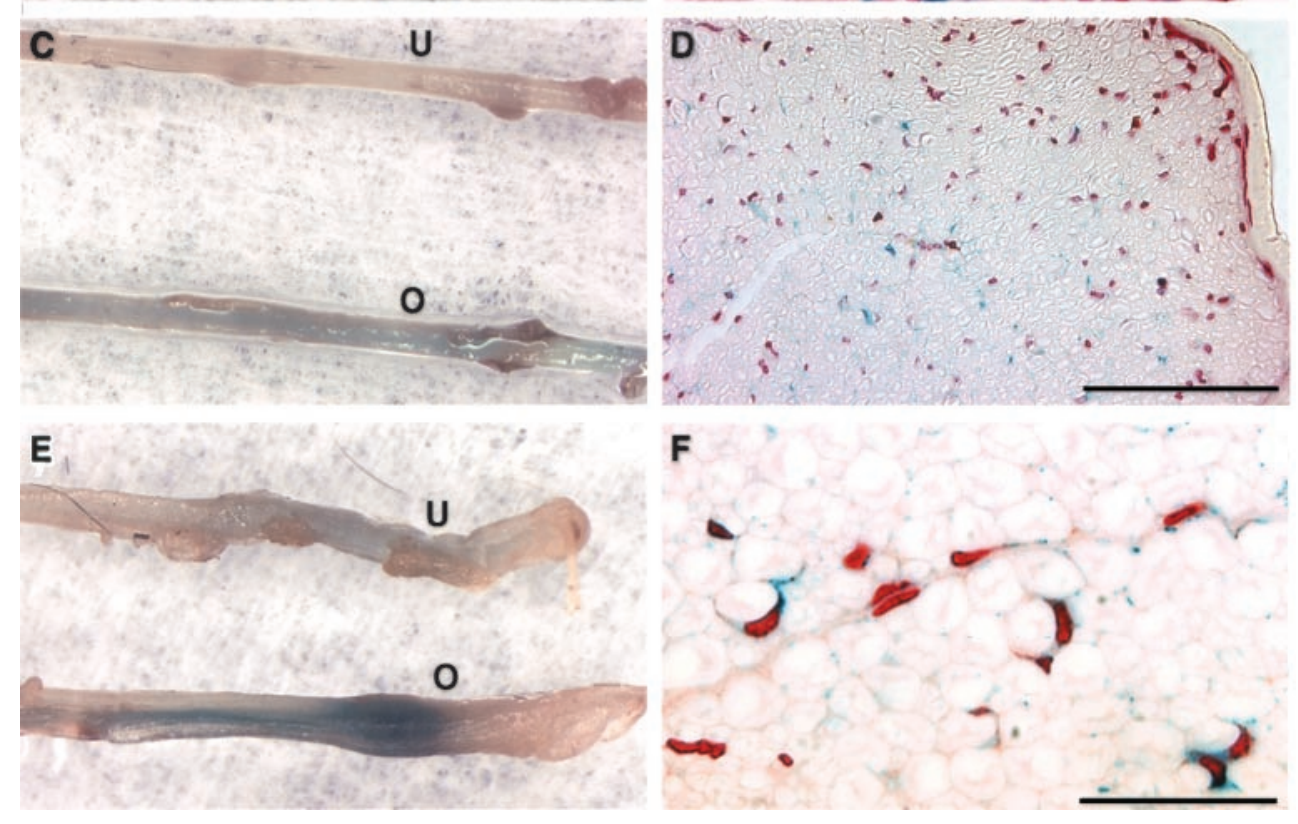

out cassette (Wallace et al., 1999), LacZ staining was performed to localize the pattern of PTP $\sigma$ expression within the regenerating nerve. Our results show that blue LacZ staining is increased in the operated nerve compared with the control contralateral unoperated nerve (Fig. 9A,C,E). LacZ staining was evident in the DRG (Fig. 9A), was increased throughout the nerve on the operated side (Fig. 9C), and was markedly intensified in the location of the advancing growth cone within the transected nerve (Fig. $9 E$ ). Figure $9 D$ reveals the expression of LacZ in a cobblestone pattern around the axons, indicating the presence of PTP $\sigma$ in the supportive milieu of the regenerating nerve. A higher magnification in Figure $9 F$ localizes LacZ staining to the Schwann cells. Unfortunately, because of a technical limitation resulting from the mode of construction of the knock-out cassette (where an internal ribosome entry site immediately precedes the $\beta$-galactosidase gene), we are not able to test for the presence of PTP $\sigma$ along the extended axons using LacZ staining. However, Figure $9 B$ does reveal LacZ staining within the sensory neurons of the DRG, as has been observed previously (Haworth et al., 1998). Thus, the regenerating nerve exhibits enhanced expression of $\mathrm{PTP} \sigma$.

\section{DISCUSSION}

Peripheral nerve regeneration was significantly faster in the PTP $\sigma(-/-)$ mouse after sciatic nerve axonotmesis injury according to all assessment techniques. In addition, the accurate navigation of the transection site after nerve division was associated with greater errors in the $\mathrm{PTP} \sigma(-/-)$ cohort compared with controls, and the environment in which the regeneration occurs (heterozygote or homozygote allograft) affects the rate of such errors.

In vitro studies have demonstrated that the state of tyrosine phosphorylation within the neuron affects the rate of neurite outgrowth. Using confocal laser-scanning microscopy and immunoelectron microscopy, Shirasu et al. (1998) demonstrated tyrosine-phosphorylated proteins concentrated in the advancing growth cones of cultured mouse DRG. Protein tyrosine kinase inhibitors such as genistein and the tyrosine phosphatase inhibitor vanadate alter in vitro neurite outgrowth in cell-culture systems (Worley and Holt, 1996; Weeks et al., 1999; Tisi et al., 2000).

The developmentally regulated expression of the LAR family PTPs (PTP $\sigma, \mathrm{PTP} \delta$, and LAR) within the mammalian nervous system (Mizuno et al., 1994; Sahin et al., 1995; Wang et al., 1995) supports a role for these enzymes in nervous system growth and development. The invertebrate LAR family PTP homologues DLAR (Drosophila) and HmLAR2 (leech) and the chicken and Xenopus CRYP $\alpha$ (homolog of PTP $\sigma$ ) localize to growth cone membranes and/or neurons during periods of axonogenesis (Stoker et al., 1995; Desai et al., 1996; Gershon et al., 1998; Johnson and Holt, 2000). This specifically suggests a role for these enzymes in neurite extension and axonal guidance. Indeed, Kreuger et al. (1996) have demonstrated defects in axonal pathfinding in DLAR-deficient Drosophila. The motor ISNb failed to exit the main intersegmental nerve trunk at a key branch point and bypassed its target muscles in the mutant fly. In the leech, disruption of HmLAR2 function with an antibody directed 
against the ectodomain (Gershon et al., 1998) or an inhibitory fusion protein (Baker et al., 2000) resulted in decreased and aberrant intersecting outgrowth of the neuron-like Comb cell trajectories. In avian and Xenopus retinal explant models, $\mathrm{CRYP} \alpha$ has been shown to modulate retinal axon extension (Ledig et al., 1999; Johnson et al., 2001).

Until now, the role of PTPs in mammalian neuronal development, and specifically axon guidance, has not been determined. The LAR knock-out mouse demonstrates a mild neurological deficit (Van Lieshout et al., 2001). The PTP $\delta$ knock-out mouse (Uetani et al., 2000) has abnormalities of long-term potentiation, and PTP $\sigma$ knock-out mice (Elchebly et al., 1999; Wallace et al., 1999) demonstrate significant developmental abnormalities of the CNS and PNS. To further investigate the role of PTP $\sigma$ in the mammalian PNS, the response of the sciatic nerve to three standardized models of nerve injury and repair was assessed. Studies evaluating nerve regeneration contribute to the understanding of developmental mechanisms because many of the processes responsible for neuronal development are recapitulated during peripheral nerve regeneration (McComas, 1996).

The sciatic nerve crush model for axonotmesis injury challenges the motor and sensory axons to regenerate to their targets; however, the intact endoneurial sheath minimizes pathfinding requirements. After crush injury we found an increased rate of nerve regeneration in $\mathrm{PTP} \sigma(-/-)$ mice compared with $\mathrm{PTP} \sigma(+/-)$ or $\mathrm{PTP} \sigma(+/+)$ mice, as determined by histologic, electrophysiologic, and neuromuscular testing. This work therefore assigns $\mathrm{PTP} \sigma$ a negative regulatory role in axonal regenerative growth. The loss of PTP $\sigma$ results in an increased rate of peripheral nerve regeneration.

Using the same model of nerve injury applied to the LARdeficient mouse, Xie et al. (2001) found that the loss of LAR significantly decreased the rate of sciatic nerve regeneration. Therefore in mammals the various members of the PTP LAR family seem to serve unique roles within the PNS and affect the rate of nerve regeneration differentially. Johnson et al. (2001) reported differential effects for the LAR family members in the developing Xenopus visual system. Putative dominant-negative mutants (catalytically inactive cytoplasmic domains) of LAR, $\operatorname{PTP} \delta$, and CRYP $\alpha$ were expressed either singly or in combination in the Xenopus retinal ganglion cells (RGCs). Dominantnegative PTP $\delta$ inhibited RGC axon outgrowth, but dominantnegative CRYP $\alpha$ increased the rate of RGC axon outgrowth. The LAR construct had no effect. In an embryonic avian visual system, blocking of the CRYP $\alpha$-putative ligand interaction with an anti-CRYP $\alpha$ antibody or ectodomain fusion protein (to block the ligand) resulted in significantly reduced axon outgrowth of the RGCs on intact basal lamina (Ledig et al., 1999). Subsequently, Johnson et al. (2001) proposed a model whereby the interaction of CRYP $\alpha$ with its ligand induces the inactivation of the CRYP $\alpha$ phosphatase activity, which results in the promotion of axon outgrowth by recruiting/activating a currently unidentified signaling cascade. Our work also shows that the loss of PTP $\sigma$ enhances axon regenerative growth. However, evidence for PTP $\sigma$ ectodomain shedding (Rotin et al., 1994; Aicher et al., 1997) and the fact that the PTP $\sigma$-deficient mouse is a full-length knock-out lacking both the CAM-like ectodomain and the intracellular phosphatase domains (Wallace et al., 1999) does not allow us to conclude that it is specifically the downregulation of catalytic activity that alters axon regeneration within the mammalian PNS.

We also conclude from histologic assessment of both the transection with immediate repair and transection with allograft models that peripheral nerve regeneration in the $\mathrm{PTP} \sigma(-/-)$ mouse shows errors in axonal guidance. The transection injury model challenges both regeneration and axon pathfinding because of the disruption of the endoneurial sheath with loss of axon alignment. We noted an increased proportion of extrafascicular regenerating axons and more fiber misdirection in the $\mathrm{PTP} \sigma(-/-)$ mice compared with $\mathrm{PTP} \sigma(+/-)$ or $\mathrm{PTP} \sigma(+/+)$ mice. These observations are in keeping with the presence of abnormal axon guidance in the Drosophila DLAR loss-offunction mutant (Krueger et al., 1996) and misdirection of Comb cell processes in the leech in which HmLAR2 is inactivated (Baker et al., 2000).

The transection and allograft model also permitted evaluation of the relative importance of PTP $\sigma$ expression in the regenerating milieu on axon guidance. $\mathrm{PTP} \sigma(+/-)$ and $\mathrm{PTP} \sigma(+/+)$ controls demonstrated normal parallel axonal regeneration in the proximal and distal nerve (where PTP $\sigma$ is expressed within the environment) yet lost direction when traversing the $\mathrm{PTP} \sigma(-/-)$ graft (an environment lacking $\mathrm{PTP} \sigma)$. In contrast, the $\mathrm{PTP} \sigma(-/-)$ animals consistently demonstrated regenerating axon guidance errors that partially corrected when the $\mathrm{PTP} \sigma(-/-)$ axons traversed the heterozygote/wild-type allografts (i.e., an environment expressing $\mathrm{PTP} \sigma$ ). Thus, the expression of $\mathrm{PTP} \sigma$ in the regenerating milieu clearly appears to be required for regenerating axons to avoid directional errors.

LacZ staining patterns demonstrated the presence of PTP $\sigma$ within the Schwann cell and the supportive matrix of the regenerating nerve. The Schwann cell is a key player in the environment of the axon and provides a supportive, growth-promoting medium during regeneration. In contrast, Haworth et al. (1998), using in situ hybridization, were unable to demonstrate the presence of PTP $\sigma$ in the neuronal support cells of the rat DRG after sciatic nerve crush. In that model, upregulation of PTP $\sigma$ expression occurred exclusively within the DRG sensory neurons. The reason for the apparent discrepancy is unclear, but it may result from different methodologies used or the region (DRG vs regenerating growth cone) assessed.

Although the presence of PTP $\sigma$ within the regenerating environment is essential to correct axon pathfinding, the advancing growth cone may not require, or can adapt to, the absence of $\mathrm{PTP} \sigma$. This is suggested by the partial correction of PTP $\sigma(-/-)$ regenerating axon trajectories within the heterozygote/wild-type allografts. The presence of both homophilic and heterophilic interactions occurring within the LAR family PTPs that regulate axonal outgrowth has been demonstrated. For example, Baker et al. (2000) have shown that homophilic interactions between HmLAR2 molecules on the growth cones of the leech Comb cells maintain their extending trajectories in a normal parallel pattern distant from their neighbors. $\mathrm{PTP} \delta$ has been shown to be a homophilic neurite promoting cell-adhesion molecule for CNS neurons (Wang and Bixby, 1999; Sun et al., 2000). In contrast, heterophilic interactions have been proposed for CRYP $\alpha$ expressed in RGCs, with cell- and matrix-associated ligands along the retinotectal projection (Haj et al., 1999). One can therefore speculate that the errant fibers in the $\operatorname{PTP} \sigma(-/-)$ mice require a heterophilic interaction to correctly cross the transection site and enter the endoneurial compartment of the graft or distal stump. Proper axonal guidance necessitates the expression of PTP $\sigma$ within the environment of the regenerating axon, but its presence on the advancing growth cone is not required for the select process of directional navigation. Other CAMs, including other LAR family members, may fulfill this role on the growth cone. 
Alternatively, we cannot exclude the possibility that PTP $\sigma$ homophilic interactions occur within the mammalian PNS. In this scenario, PTP $\sigma$ plays an important role within the regenerating environment, but one could speculate that a closely related LAR family member could substitute for the loss of PTP $\sigma$ on the growth cone and "rescue" the PTP $\sigma$-deficient axon. Definitive determination of the mechanism involved awaits the identification of the ligand and substrate for PTP $\sigma$. In Drosophila, the precise axonal responses of ISNb to guidance cues in the environment are likely controlled by the collaboration between the tyrosine kinase Abl and its substrate Enabled, balanced by the PTP DLAR (Wills et al., 1999). Unfortunately, the substrate(s) and ligand(s) for PTP $\sigma$ and the signaling pathways involved to regulate its effects on neuronal growth and function are unknown.

The quiescent sciatic nerve of the $\mathrm{PTP} \sigma(-/-)$ mouse does not demonstrate an increased proportion of extrafasicular fibers and possesses a normal well organized perineurium (Wallace et al., 1999). This is likely attributable to the fact that during development, misdirected and improperly targeted neurites and fibers within the PNS are pruned and therefore would not be seen in the postnatal animal.

In summary, we have demonstrated a critical role for PTP $\sigma$ in three in vivo models of peripheral nerve injury, repair, and regeneration. The loss of $\mathrm{PTP} \sigma$ results in faster peripheral nerve regeneration and significant abnormalities of axon guidance. The definitive mechanism responsible and the signaling pathways involved await identification of ligand(s) and substrate(s) for PTP $\sigma$.

Note added in proof. Since the acceptance of this paper, a recent report has identified two ligands for CRYP $\alpha(\mathrm{PTP} \sigma)$ (Aricesku et al., 2002).

\section{REFERENCES}

Aicher B, Lerch MM, Muller T, Schilling J, Ullrich A (1997) Cellular redistribution of protein tyrosine phosphatases LAR and PTP $\sigma$ by inducible proteolytic processing. J Cell Biol 138:681-696.

Aricesku AR, McKinnell IW, Halfter W, Stoker AW (2002) Heparan sulfate proteoglycans are ligands for receptor tyrosine phosphatase sigma. Mol Cell Biol 22:1881-1892.

Bain JR, Mackinnon SE, Hunter DA (1989) Functional evaluation of complete sciatic peroneal and posterior tibial nerve lesions in the rat. Plast Reconstr Surg 83:129-136.

Baker MW, Rauth SJ, Macagno ER (2000) Possible role of the receptor protein tyrosine phosphatase HmLAR2 in interbranch repulsion in a leech embryonic cell. J Neurobiol 45:47-60.

Baldwin TJ, Faxeli MS, Doherty P, Walsh FS (1996) Elucidation of the molecular actions of NCAM and structurally related cell adhesion molecules. J Cell Biochem 61:502-513.

Batt J, Asa S, Fladd C, Rotin D (2002) Pituitary, pancreatic, and gut neuroendocrine defects in protein tyrosine phosphatase $\sigma$ deficient mice. Mol Endocrinol 16:155-169.

Bixby JL (2000) Receptor tyrosine phosphatases in axon growth and guidance. NeuroReport 11:R5-R10.

Brown CJ, Evans PJ, Mackinnon SE, Bain JR, Makino AP, Hunter DA, Hare GMT (1991) Inter- and intraobserver reliability of walking-track analysis used to assess sciatic nerve function in rats. Microsurgery 12:76-79.

Desai CJ, Gindhart Jr JG, Goldstein LSB, Zinn K (1996) Neural receptor tyrosine phosphatases are required for motor axon guidance in Drosophila embryo. Cell 84:599-609.

Doering LC (1992) Appropriate target interactions prevent abnormal cytoskeletal changes in neurons: a study with intrasciatic grafts of the septum and hippocampus. J Neurosci 12:3399-3413.

Elchebly M, Wagner J, Kennedy T, Lanctot C, Michaliszyn E, Itie A, Drouin J, Tremblay ML (1999) Neuroendocrine dysplasia in mice lacking protein tyrosine phosphatase $\sigma$. Nat Genet 21:330-333.

Gershon TR, Baker MW, Nitabach M, Macagno ER (1998) The leech receptor protein tyrosine phosphatase HmLAR2 is concentrated in growth cones and is involved in process outgrowth. Development 125:1183-1190.
Goodgold J, Eberstein A (1983) Electrodiagnosis of neuromuscular diseases. Baltimore: Williams and Wilkins.

Haj F, McKinnell IW, Stoker A (1999) Retinotectal ligands for the receptor tyrosine phosphatase CRYP- $\alpha$. Mol Cell Neurosci 14:225-240

Hare GMT, Evans PJ, Mackinnon SE, Best TJ, Bain JR, Szalai JP, Hunter DA (1992) Walking track analysis: a long-term assessment of peripheral nerve recovery. Plast Reconstr Surg 89:251-258.

Hare GMT, Evans PJ, Mackinnon SE, Best TJ, Midha R, Szalai JP, Hunter DA (1993) Walking track analysis: utilization of individual footprint parameters. Ann Plast Surg 30:147-153.

Haworth K, Shu KK, Stokes A, Morris R, Stoker A (1998) The expression of receptor tyrosine phosphatases is responsive to sciatic nerve crush. Mol Cell Neurosci 12:93-104.

Johnson KG, Holt C (2000) Expression of CRYP- $\alpha$, LAR, PTP- $\delta$, and PTP- $\rho$ in the developing Xenopus visual system. Mech Dev 92:291-294.

Johnson KG, McKinnell IW, Stoker AW, Holt CE (2001) Receptor protein tyrosine phosphatases regulate retinal ganglion cell axon outgrowth in the developing Xenopus visual system. J Neurobiol 49:99-117.

Krueger NX, Van Vactor D, Wan HI, Gelbart WM, Goodman CS, Saito H (1996) The transmembrane tyrosine phosphatase DLAR controls motor axon guidance in Drosophila. Cell 84:611-622.

Lang TA, Secic M (1997) How to report statistics in medicine: annotated guidelines for authors, editors, and reviewers. Philadelphia: American College of Physicians.

Ledig MM, Haj F, Bixby JL, Stoker A, Mueller BK (1999) The receptor tyrosine phosphatase CRYP- $\alpha$ promotes intraretinal axon growth. J Cell Biol 147:375-388.

McComas AJ (1996) Recovery of muscle innervation. In: Skeletal muscle, form and function, pp 259-272. Champaign, IL: Human Kinetics.

Mizuno K, Hasegawa K, Ogimoto M, Katagiri T, Yakura H (1994) Developmental regulation of gene expression for the MPTP $\delta$ isoforms in the central nervous system and the immune system. FEBS Lett 355:223-228.

Robertson A, Day B, Pollock M, Collier P (1993) The neuropathy of elderly mice. Neuropathology 86:163-171.

Rotin D, Fladd C, Goldstein BJ (1994) Expression of the tyrosine phosphatase LAR-PTP2 is developmentally regulated in lung epithelia. Am J Physiol 267:L263-L270.

Rutishauser U, Gall WE, Edelman GM (1978) Adhesion among neural cells of the chick embryo. IV. Role of the cell surface molecule CAM in the formation of neurite bundles in cultures of spinal ganglia. J Cell Biol 79:382-393.

Sahin M, Dowling JJ, Hockfield S (1995) Seven protein tyrosine phosphatases are differentially expressed in the developing rat brain J Comp Neurol 351:617-631.

Schaapveld RQ, Schepens JT, Bachner D, Attema J, Wieringa B, Jap PH, Hendriks WJ (1998) Developmental expression of the cell adhesion molecule-like protein tyrosine phosphatases LAR, RPTP $\delta$, and RPTP $\sigma$ in the mouse. Mech Dev 77:59-62.

Seddon HJ (1943) Three types of nerve injury. Brain 66:238-288.

Shirasu M, Morihara T, Okajima S, Tamai K, Mizoguchi A, Ide C, Hirajawaw Y (1998) Localization of tyrosine-phosphorylated proteins in cultured mouse dorsal root ganglion neurons. J Orthop Res 16:690-696.

Smorto MP, Basmajian JV (1979) Introduction to nerve conduction tests. In: Clinical electroneurography, pp 19-56. Philadelphia: Williams and Wilkins.

Sternberger LA, Sternberger NH (1983) Monoclonal antibodies distinguish phosphorylated and non-phosphorylated forms of neurofilaments in situ. Proc Natl Acad Sci USA 80:6126-6130.

Stoker A (2001) Receptor tyrosine phosphatases in axon growth and guidance. Curr Opin Neurobiol 11:95-102.

Stoker AW, Gehrig B, Haj F, Bay BH (1995) Axonal localisation of the CAM-like tyrosine phosphatase CRYP $\alpha$ : a signalling molecule of embryonic growth cones. Development 121:1833-1844.

Sun QL, Wang J, Bookman RJ, Bixby JL (2000) Growth cone steering by receptor tyrosine phosphatase $\delta$ defines a distinct class of guidance cue. Mol Cell Neurosci 16:686-695.

Tisi MA, Xie Y, Yeo TT, Longo FM (2000) Downregulation of LAR tyrosine phosphatase prevents apoptosis and augments NGF-induced neurite outgrowth. J Neurobiol 42:477-486.

Uetani N, Kato K, Ogura H, Mizuno K, Kawano K, Mikoshiba K, Yakura K, Asano M, Iwakura Y (2000) Impaired learning with enhanced hippocampal long-term potentiation in PTP $\delta$ deficient mice. EMBO J 19:2775-2785.

Van Lieshout EM, Van der Heijden I, Hendriks WJ, Van der Zee CE (2001) A decrease in size and number of basal forebrain cholinergic neurons is paralleled by diminished hippocampal cholinergic innervation in mice lacking leukocyte common antigen-related protein tyrosine phosphatase activity. Neuroscience 102:833-841.

Van Vactor D (1998) Adhesion and signaling in axonal fasciculation. Curr Opin Neurobiol 8:80-86. 
Van Vactor D, O'Reilly AM, Neel BG (1998) Genetic analysis of protein tyrosine phosphatases. Curr Opin Genet Dev 8:112-126.

Wallace MJ, Batt J, Fladd CA, Henderson JT, Skarnes W, Rotin D (1999) Neuronal defects and posterior pituitary hypoplasia in mice lacking the receptor tyrosine phosphatase PTP $\sigma$. Nat Genet 21:334-338.

Wang H, Yan H, Canoll PD, Silvennoinen O, Schlessinger J, Musacchio JM (1995) Expression of receptor protein tyrosine phosphatase- $\sigma$ (RPTP- $\sigma$ ) in the nervous system of the developing and adult rat. J Neurosci Res 41:297-310.

Wang J, Bixby JL (1999) Receptor tyrosine phosphatase- $\delta$ is a homophilic, neurite-promoting cell adhesion molecule for CNS neurons. Mol Cell Neurosci 14:370-384.
Weeks BS, Wilson PJ, Heffernan CC, Gorra VA, White LE, Ahmad A (1999) Laminin stimulates protein tyrosine dephosphorylation in PC12 cells. Biochem Biophys Res Commun 262:713-719.

Wills Z, Bateman J, Korey CA, Comer A, Van Vactor D (1999) The tyrosine kinase Abl and its substrate enabled collaborate with the receptor phosphatase Dlar to control motor axon guidance. Neuron 22:301-312.

Worley T, Holt C (1996) Inhibition of protein tyrosine kinases impairs axon extension in embryonic optic tract. J Neurosci 16:2294-2306.

Xie Y, Yeo TT, Zhang C, Yang T, Yang T, Tisi MA, Massa SM, Longo FM (2001) The leukocyte common antigen-related protein tyrosine phosphatase receptor regulates regenerative neurite outgrowth in vivo. J Neurosci 21:5130-5138. 